\section{Military Technical College Kobry El-Kobbah, Cairo, Egypt}

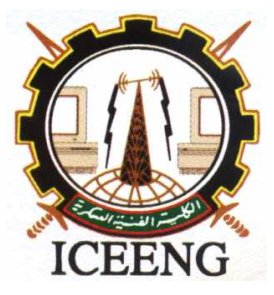

\title{
Power system modeling, simulation and analysis
}

\author{
By \\ Dr.Taj Mohammad Baloch* Ku Maziana KuMamat** Mas Rizal bin Abd Rahim ***
}

\section{$\underline{\text { Abstract: }}$}

Power system studies and analysis are performed for a variety of reasons. One of them is to ascertain whether the designed power system is stable for operation. Many research and calculations for this purpose need to be carried by the electrical engineer. Currently available software can be used to perform various calculations and studies besides providing a means to simulate the model power system using a minimal amount of time. Power system simulation is used to simulate the model of power system using appropriate software that is commonly used in the industrial process and power plant. It covers the development and application of methods for system analysis, simulation, and control of integrated electric energy system. It also includes modeling of generation, transmission, distribution systems in addition the operation and planning of electric power system. The present paper investigates the current issues and challenges in power system modeling and simulation. The most important is the case of a newly built power system network which has been designed and modeled. The power system analysis functions include load flow, fault analysis, short circuit tests, protection and coordination.

\section{Keywords:}

Modeling and Simulation, Load flow, System Fault, Protection coordination

* Electrical and Electronic Engineering Department

Universiti Teknologi PETRONAS, 31750, Bandar Seri Iskandar, Perak Malaysia Ph: +60-3687828, Fax: +60-5-3657443

*tajmbaloch@petronas.com.my, **miss_maziana@yahoo.com,***masrizal@gmail.com 


\section{Introduction:}

Modern large-scale electric power systems are the most complex technical systems developed and built by mankind using modern technology. It has main goal of providing continuous electric power supply to the facilities with little or no interruptions. For a power system to be practically useful it must be safe, reliable and economical. Power system engineers are encountering nowadays with a variety of problems regarding design, operation and control. In order to provide the reliability required by the dependence of continuous electric service, it is necessary that power systems are designed to be stable and protected under any conceivable disturbances. Design of a power system, its operation and expansion requires much analysis. To solve these problems the engineers need powerful computer aided tools, which require different kind of models to study the effects of various disturbances in a power system [1].

The design of electrical power system can be divided into three major parts:

i. Generation, the production of electricity

ii. Transmission, the system of lines that transport the electricity from the generating plants to the area in which it will be used

iii. Distribution, the system of lines that connect the individual customer to the electric power system.

Electrical protection is designed to detect and disconnect faulted electrical circuits and as such, is a key element in providing a safe work environment. The design, installation and maintenance of electrical protection is complicated and should it only be carried out by competent electrical engineers[3],[4],[5].

\section{Methodology and Project Work}

The present project for modeling an electric power system has gone through few stages of design procedures. Literature review was conducted concerning the elements of power system. This was to gain the necessary knowledge involved, issues and challenges before embarking on the design and simulation stage of the project. Beside that application of ERACS software and other power system modeling, analysis and simulation software was also studied.

In case of the design stage of the project, data from various sources were obtained. Most of the data on the electrical components used in the simulation were chosen from the ERACS software reference library, catalogues ect.

The power system design was based on the guidelines obtained from literature review 
and software application. From the basic network, it was refined and improved until the final design was completed. The network was then simulated using ERACS software. This involved a series of tests to determine the load flow parameters, fault analysis and also short circuit current within designed network. Once the network was finalizing, power system study and testing was performed.

The economical design of power system is critically dependent on being able to predict the system behavior under both normal and abnormal operating conditions. Manual calculations and estimates are possible but they increase in engineers' time and run the risk of introducing errors resulting in significant safety and reliability implications. ERACS software is suitable for power system analysis. It saves costs, reduces risk, improves system quality and increases reliability and safety too.

The data in ERACS software is entered once only in a central database system, making data management a very simple procedure. Networks for simulation by ERACS software may be either radial or fully interconnected systems or a mixture of both.

\section{Modeling and Simulation}

The designed model of power system network developed is shown in Figure.2. It is an interconnected network, where three incoming power supply feeders are connected to three substations. An interconnected system provides continuous service even when one of the power station is shut down. One of the main advantages of the interconnection is increased security of services; another is the reduction in stand-by plant, and third is the economy obtained by dividing the total load in such a way as to reduce the total capital cost and running costs to a minimum [2].

The model network is divided into three major zones which are heavy industrial load, industrial and commercial load and residential load. The load data was indicated in term of P/Q load, admittance, constant current and impedance load. The $66 \mathrm{kV}$ power system network consists most of the elements which are used in designing, modeling and simulating the power system. There are:

- Busbars $(66 \mathrm{kV}, 22 \mathrm{kV}, 33 \mathrm{kV}, 11 \mathrm{kV}, 3 \mathrm{kV}$ and $415 \mathrm{~V})$

- 3 Bus-sections

- Synchronous machines: generator and motor

- Induction machines: generator and motor

- Mechanical load

- Neutral earthling 
- Transformer: 2 and 3 winding

- On load tap charger

- Shunt loads: fixed PQ, admittance, and impedance

- Switch/circuit breaker

The model was configured such that the three phase fault level provided by the grid is not effected by connected load. The main inputs for the bus bars are the voltage rating in $\mathrm{kV}$ and frequency in $\mathrm{Hz}$. The transformer model includes one record per winding data interface (Figure 1) and a dummy bus-bar to which all windings are connected. Each winding is represented by a leakage impedance and includes both no load voltage ratio and off nominal tap.

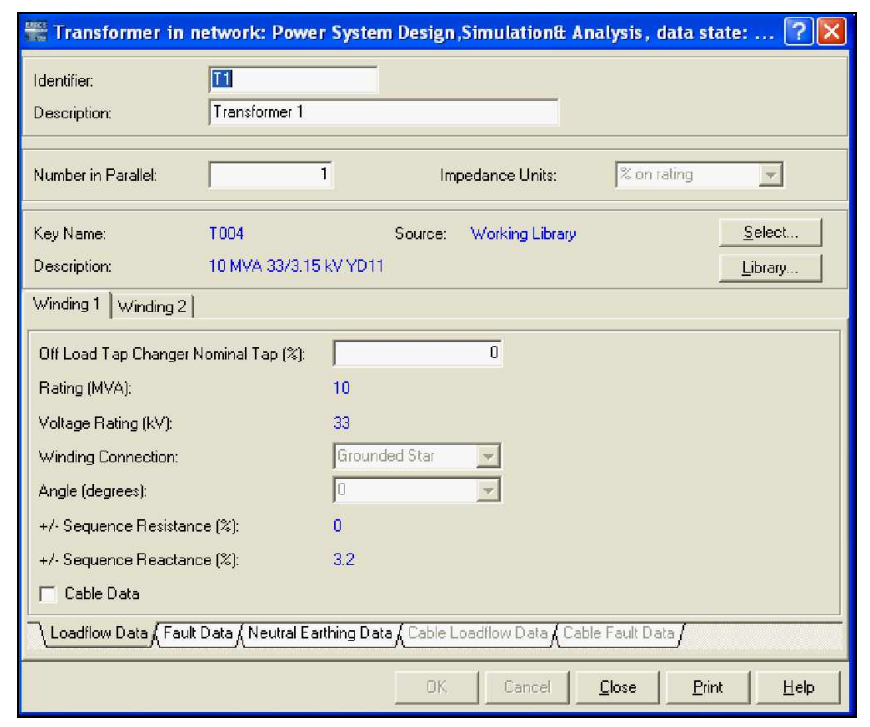

Figure (1): Input Interface for transformers

Several studies were conducted on the network using ERACS. The studies are listed as follows:

i. Load flow studies

ii. Three phase fault survey

iii. Protection co-ordination study

\section{Load flow Simulation}

The Load flow study performs the load analysis and calculates the steady state conditions of the power system. Under given constraints the program had to determine 
the network voltage profile, current and real and reactive power flow.

By using Gaus-Seidal method the voltage at a bus bar can be computed as follow:[1]

$$
V_{i}^{(k+a)}=\frac{\frac{P_{i}{ }^{s c h}-j Q_{i}{ }^{s c h}}{V_{i}{ }^{*}(k)}+\sum^{n}{ }_{j=1} y_{i j} V^{(k)}{ }_{j}}{\sum^{n}{ }_{j=0} y_{i j}}
$$

Where ' $\mathrm{y}$ ' the actual admittance per unit of lines connected to it and P and Q are also expressed in per unit value. The convergence is achieved by modifying the voltage magnitude and angle of the synchronous machines, the tap position of on load tap chargers, and the slip for induction machines. As mentioned before, load flow study must be carried out before any other study or calculation being started. This is because load flow converts the network database into a format that is easier and faster to access. The converted data is used along with the initial condition for other calculation purposes. The simulation of the system model has been carried out and some of the results are shown in Figure 2 and Figure 3.

According to the simulation, the results obtained show total generated real power, reactive power, total power in each line in MW and MVar and power losses occurred in the lines. It has also calculated the voltage rating at all bus bars for existing condition. The highest voltage ratings are generally at the sending-end of the network. 


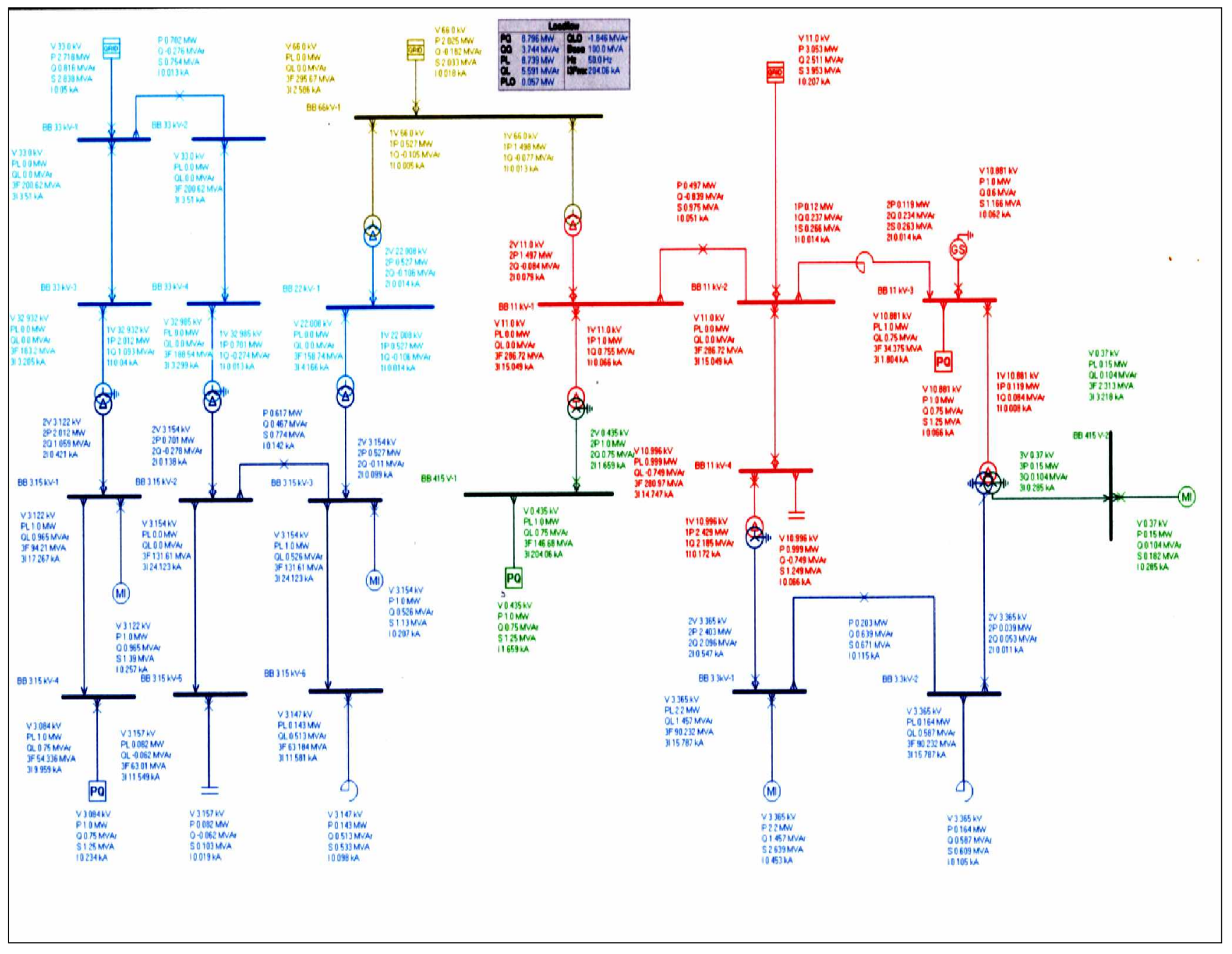

Figure (2) : Power system simulation results

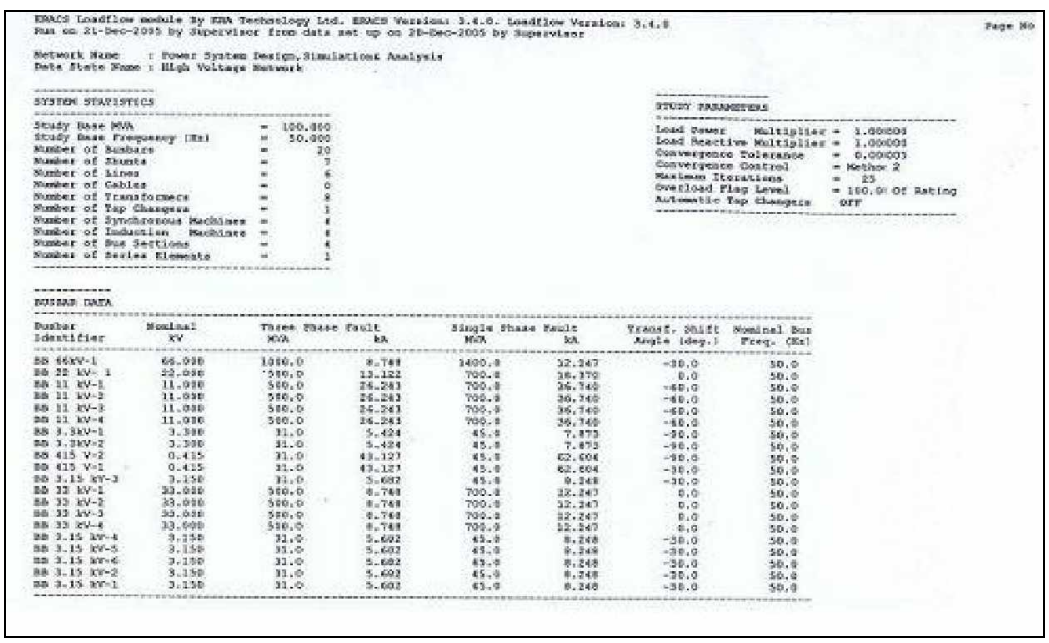

Figure(3): Load flow study results 


\section{Fault Simulation}

The fault, calculation and fault study programs enable to establish currents and voltages around a network immediately following a fault condition. Facilities are provided to simulate various type of fault such as:

- Phase to earth

- Two phase to earth

- Phase to phase

- Three phase to earth

The fault study on the model was carried out which involved application of the same type of fault to every busbar of the network. The results are as shown in Figure 4.

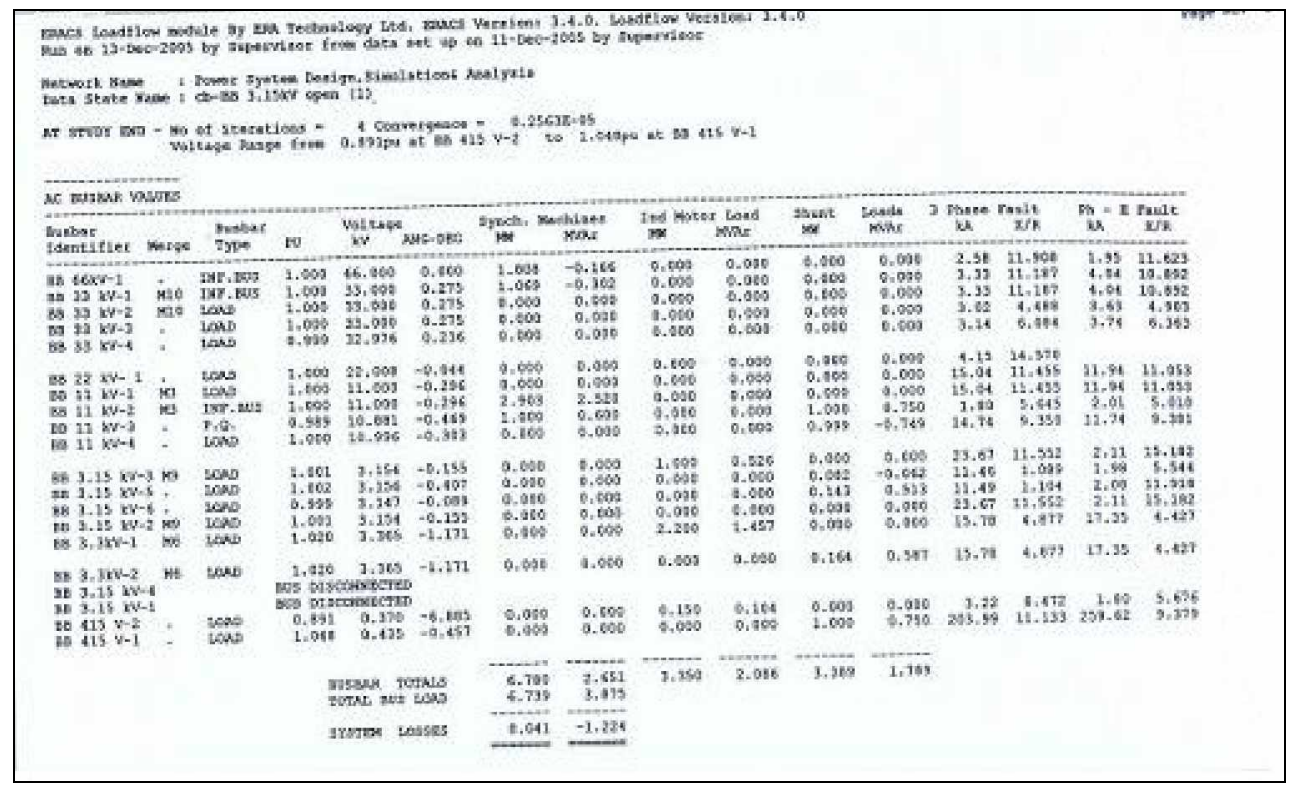

Figure(4): Fault simulation results

\section{Protection Co-ordination}

The protection co-ordination study was designed to analyze the behavior of the protection devices in the power system network, so that engineer can check that acceptable discrimination is achieved. The study includes a feature known as a stability check, where the program determines whether any protection devices will operated 
while carrying the calculated current during Load flow study and analysis. There are four types of protective device are available in ERACS software:

- Fuse

- Relay

The relay model may be used to represent both inverse definite minimum time lag (IDMTL) and standard relays.

- Circuit breaker

The circuit breaker category has been sub-divided into three categories:

i. Circuit breaker with an integral relay

ii. Circuit breaker with a direct acting release

iii. Moulded case circuit breaker

- Autorecloser

Autoreclosers are modeled by defining the auto recloser characteristic by a number of points of current against time.

The protection study has been conducted for the various fault occurrences, such as single line to earth fault, phase to phase fault and three phase fault. The summary result for status of the operation of any protection device can be highlighted in the network diagram by selecting one of the row in the Protection control panel interface shown in Figure 5.

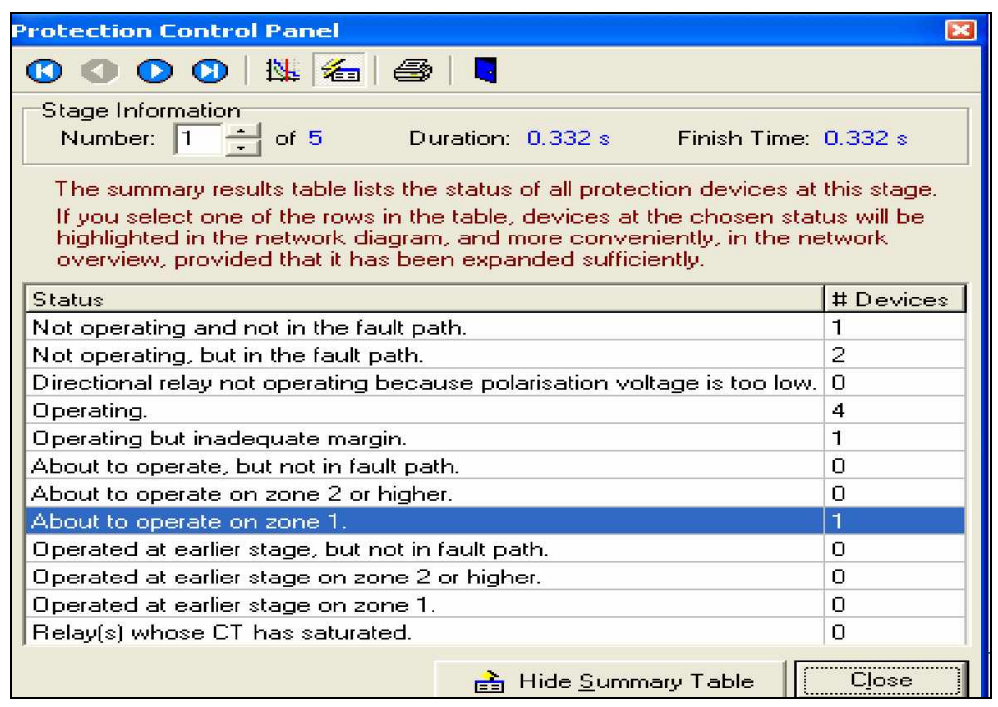

Figure (5): Protection Co-ordination simulation 


\section{Conclusion}

Modeling and simulation of power system is essential in determining the operating and technical activities of Electric Power System. It also covers development and application of different methods for analysis, simulation, and control of integrated electrical energy systems. The accuracy of the model can be determined based on input and output data.

Thus the study and research of power system simulation is important to design, model and simulate the power system analysis functions including loadflow, short circuit (in accordance with international standards), protection and coordination.

The results of power system simulation, modeling and studies are of no value unless they are implemented within the system. It can make comparison of the simulation results and the real power system.

The modeling of power system network was achieved by simulation and in depth research was carried out through load flow, short circuit and protection coordination study using ERAC software which enabled the authors to study the issues and challenges in design of the power system and its stability. It can be concluded that the simulation studies are crucial in the design of power system. Simulation studies improve the quality of routines design and allows the engineer to asses the performance of the power system not only during the design stage, but also in case when the system already operating. The result obtained during simulation of the system model are comparable to existing power system and it can be used to further apply its application in improving the performance of existing power systems in varying load condition. It can also be applied in predicting the future performance of an existing power system by adding new load, transmission and distribution line etc [5].

\section{Recommendation}

The occurrence of voltage drop along transmission line and distribution lines is common in electrical power system. It is essential that the voltage at the consumers' terminal be within narrow limits as the consumer's appliances are sensitive to voltage. A rise in supply voltage may burn out lamps and motors, and a drop will cause unsatisfactory operation. The simulation should be extended to test the effects of adding shunt capacitors and synchronous generators to improve voltage at the receiving end of the distribution line. 


\section{References:}

[1] Hadi Saadat, 2004. Power System Analysis Mc-Graw-Hill International Editions.

[2] Taj Mohammad Baloch, Tumisang Penelope,"A case study in Power System Transmission Modeling and Simulation” ICIS'2005, Universiti Teknologi PETRONAS, Malaysia

[3] Professor A.T. Jones, Dr. A. Ter-Gazarian, D.F.Warne, Juan M.Gers and Edward J. Holmes, IEE Power and Energy Series 28, Protection of Electricity distribution Networks

[4] Power System Protection, Volume 3: Application, the Institution of Electrical Engineers, United Kingdom.

[5] J. Lewis Blackburn, Protective Relaying, Principles and Applications, Second Edition, Marcel Dekker, Inc. 